\title{
Video as a Research Tool to Analyse Interactions around Media in Households
}

\author{
Sarah Martindale, Tim Coughlan \\ Horizon Digital Economy Research, University of Nottingham \\ University of Nottingham Innovation Park, Triumph Road, Nottingham NG7 2TU \\ \{Sarah.Martindale;Tim.Coughlan\}@nottingham.ac.uk
}

\begin{abstract}
In this paper we explore the value of capturing and analysing video data, and the challenges faced with 'in the wild' contexts. More specifically we review issues raised through prior research to develop an approach that seeks to understand how contemporary households interact with, and around, multiple screens, devices and media platforms. The nature of this topic leads us to consider how video is conceptualised and analysed in film and television studies, and the value this understanding can have to $\mathrm{HCl}$, particularly as media consumption and computer use become more intertwined through online streaming, interactive television, companion applications and integration with social media.
\end{abstract}

Video. Media. Household. Multiple screens. Device ecologies. Methodology. Interdisciplinary.

\section{INTRODUCTION}

Video has provided a significant resource for many forms of Human-Computer Interaction research. It is capable of capturing the fundamental object of study - interaction - in a rich form, both between people and computers, and also between people, mediated by technology. It has been used variously as a document from which researchers extract selected examples or vignettes that are used individually to support arguments, for content analysis that has quantified specific actions across masses of source material, or for in-depth micro analysis of short segments of interaction. Video also commonly has secondary uses, such as providing material for illustrating, presenting or promoting $\mathrm{HCl}$ research projects, or as a means of checking the accuracy or understanding the context of other forms of data.

Some distinctions can be drawn in that, when compared to many of the other data sources used in $\mathrm{HCl}$ research such as survey responses, diary studies or automated logs of activity, video brings with it greater general understanding and use among the public. Most of us view extensive amounts of video every day, and the capture of video and its production and dissemination to inform and entertain is a process that is central in modern life and society. Video is also a topic that can incite strong responses, from concern over the proliferation of CCTV, through to the emergence of citizen journalism where footage captured by members of the public becomes part of mainstream me- dia. For both participants and researchers there are likely to be ill-defined overlaps between the capture and use of video as research data, and video as it exists more generally in the world with its many uses, processes and norms.

In this context, a project that aims to study media consumption in households by observing interactions with screen devices presents multiple challenges alongside strong reasons to capture video in various forms. In the following sections we draw on literature to provide a background to these challenges and also as a means of conceptualising the capture, analysis and use of video data in research about media. We then describe our approach for the 'Understanding the Multi-Screen Household' (UMH) project, which explores research questions - relevant to $\mathrm{HCl}$ and television studies - about the proliferation of connected technologies now being used to access and interact with media content. The project will study natural behaviours with video, combining this with data collected on home network activity and through self-reporting. The project team comprises individuals with prior experience of using video in ethnographies of technology use (Reeves, 2011) and design and evaluation studies in $\mathrm{HCl}$ (Coughlan et al., 2012), and individuals with prior experience of qualitative research about attitudes towards new media (Evans, 2011) and the role of media consumption in wider patterns of social and cultural life (Martindale, 2008). As such the methodology being actively developed is interdisciplinary, and intended to facilitate the examination of interactions involving technology and content. 


\section{BACKGROUND}

In film and television studies audio-visual material is normally a pre-existing artefact subjected to analysis, rather than data generated and collected as part of the research method. Reference to Deacon et al.'s (1999) practical guide to methods in media and cultural analysis, gives a broad overview of the ways in which video is conceptualised and analysed in this field: as media content, as a form of observation and as a record of interactions. The point is made that the textual analysis of video in terms of its content may not take into account circumstances of production and reception. This drawback is made very obvious in critiques of media effects research (e.g. Gauntlett, 2001), which argue that counting the number of instances of violence in a media text is not a useful measure of its harmfulness because of the lack of context (children's cartoons, for example, frequently contain many acts of violence).

Observation is recommended as a means of studying media as cultural products; video is identified as a potential method to document experiences, but it is not seen as a suitable substitute for a researcher's presence in the research environment. Another approach to video is as a source of media talk, communicative exchanges (e.g. political debates) that can be closely scrutinised using conversation or discourse analysis. These tightly focused methods can be complemented by others that locate specific instances of talk within wider social, cultural and historical contexts.

Within the broad spectrum of media analysis, there is a tradition of research that seeks to understand how television as technology and content functions as part of lived social and cultural experience. An early example is Family Television by David Morley (1986), a project that set out to 'identify and investigate the differences hidden behind the catch-all description "watching television"' (39). In order to gain qualitative insights into the criteria informing viewing choices and responses Morley conducted collective interviews with eighteen families in their own homes, discursively exploring and then analytically unpacking reported behaviour.

In a more recent study in this vein Helen Wood (2007) extended Morley's methods when considering the impact of digital developments on the social use of television, employing a methodology she calls 'text-in-action', which combines video recordings of television viewed, audio recordings of sound in the home during this viewing and interviews with participants about their television consumption. In her study two evenings of television usage (as a process of content and platform navigation) and concurrent conversation in fifteen homes were recorded and combined in an inte- grated transcript. This approach allowed the researcher to examine the complex ways in which viewing as a process in time is shaped by content, technology and social interaction in combination.

Because television is an industry that actively seeks to engage consumers with content and technology, there is research interest beyond the academy that seeks to understand what provokes engagement, in order to better manage and promote it. For example, since 2005 the UK media regulator, Ofcom, has annually commissioned The Knowledge Agency to conduct qualitative research, Media Lives $(2010,2011)$, as a complement to their quantitative surveys of adults' media literacy. This takes the form of an ethnographic video study in which between twelve and eighteen individual participants are interviewed in their homes about digital media, which allows for some demonstration and/or observation of their media use as part of the process. In this case video is used as the main vehicle for the presentation of findings in the form of an edited debrief documentary, and clips are also organised into a reference databank.

Another independent research company, Actual Customer Behaviour (2006), undertook videobased research in collaboration with London Business School into eight families' television viewing behaviour in the natural setting of their homes. This involved placing a camera and microphone in the lounge linked to a picture-in-picture unit recording what simultaneously appeared on the television screen. The purpose of doing so was to determine whether those watching time-shifted programming using their personal video recorder habitually fastforward through advertisements and consequently are unaware of them. The insights and issues that emerged from ethnographic analysis of edited footage informed filmed in-home follow-up interviews, during which video clips were also shown to participants in order to encourage in-depth responses to the questions. In addition, detailed coding of micro-behaviours observed on the video enabled quantitative analysis of the qualitative sample that was compared with available large-scale statistically representative data.

\section{CHALLENGES TO USING AND ANALYSING VIDEO IN STUDIES OF HOUSEHOLDS}

Having considered previous research methods for investigating the use of media in households, it is clear that video can play a useful role in such work. But before employing video as a research tool it is important to acknowledge the challenges that this poses. In studies undertaken 'in the wild' researchers are purposefully unwilling to control aspects of the context of study in the way that a lab-based experiment would. We must therefore accept that 
certain choices that would make for better data capture are actually inappropriate in that they would be detrimental to the activity and context. For example when we talk about video we implicitly mean images and sound, and audio is often a focus for analysis activities (as in Wood, 2007). In reality, capturing the voices of multiple users, alongside background sounds, is difficult, particularly for a project that focuses on media use when the contribution of electronic devices to the audio environment is of great significance also. However, we must simultaneously be sensitive that approaches to making capture more effective (e.g. attaching microphones to individuals) would have consequences for the participants.

Houses also present varied physical spaces with different configurations of rooms, technologies and people at any time. Any video only reflects certain angles on this space, which must be chosen with negotiation or at least agreement with the participants. Thus, while we might like to consider video as capturing some objective truth or reality, we must also reflect that video only presents limited angles, with much of the context in which events occur known and felt only by the participants, rather than being a complete record of a particular event or experience, as Pink (2007) stresses. The home presents a context where privacy and personal space have to be considered paramount (particularly if we hope to observe an approximation of natural behaviour without our intervention).

There is a close overlap between the object of study - interactions around video media - and video as a method of capturing data. A holistic view of the role of participants in data capture could be particularly valuable here: What control do we give participants over capture? How are their actions affected by their perceptions of what it means to be filmed and what are their expectations of how the results will be used? On television, video of people going about their everyday lives features in a wide range of genres, from fly-on-the-wall documentaries like Educating Essex to structured/scripted reality shows like The Only Way is Essex. Studies of reality television (Hill, 2005) indicate that viewers are aware that video does not represent objective truth but enjoy the process of reaching conclusions about the veracity of what they witness. It may be that research methods using video are understood to some extent within frameworks derived from media content as a process of judging and deriving truth from mediated reality.

The above challenges exist at the capture stage, before any analysis, but must be considered as a part of how we subsequently use the video. At the analysis stage, further challenges exist. The richness of video is its strength, but also can be considered problematic in that it can be difficult to make use of video data to produce succinct evidence, and communicable discussion points. Content analysis for specific actions or events can be a very time consuming process, yet often provides the only means to analyse events that are not understood in advance, or easily logged by other means, such as roles played by multiple devices in household media consumption. At the same time there is commonly a need to synthesise multiple forms of data. These could be multiple video streams, captured from different locations and with different technologies. They could also include nonvideo data such as logs of internet activity, that can be linked together to present a meaningful picture of activities, as is the intention of the UHM project.

\section{AN APPROACH TO UNDERSTANDING IN- TERACTIONS AROUND MEDIA IN MULTI- SCREEN HOUSEHOLDS}

The objective of the UMH project is to develop and apply a methodology that will allow for the observation of everyday interactions around media in as much detail as possible, bearing in mind that such interactions are becoming ever more complex and fragmented as the communal television set and broadcast schedule are augmented by additional entertainment devices (smart phones, laptops, tablets, games consoles) and platforms (PVR and streaming services, social media) that provide alternative channels for accessing and interacting with media content. As a result the experience of 'watching television' is no longer encapsulated by interactions around shared technology by colocated household members, the subject of previous research (Wood, 2007; ACB, 2006). Within the living area, and elsewhere thanks to portable devices, media interactions may now involve simultaneous consumption of a variety of content (television, games, websites) via multiple internet enabled devices and/or remote social communication.

In an attempt to capture this nuance we propose a methodology that draws on and adds to the research tools applied in previous studies. One side of this is to monitor, as far as is technically possible, what content is accessed on which devices at particular times. This will involve logging internet activity on the home network and recording the content that appears on the main household display. But in isolation this does not reveal much about the nature of the interactions taking place, which is where video as a tool is essential to the project. The other dimension of the research method is to observe the ways in which individuals in various household configurations (e.g. families, couples, single people, housemates) interact with and organise social activity around media content and technologies. The living space will be videoed in order to capture (verbal and non-verbal) commu- 
nication, physical proximity and focus of attention. The absence of individuals in this space in conjunction with logged internet activity will provide some indications about media consumption taking place elsewhere. In order to generate such insights the different types of data will need to be synchronised and synthesised. Particular choices, along with general preferences, will be explored in interviews and workshops with participants on a number of occasions during the research process.

What we want to collect is information about naturally occurring interactions that take place around media in the domestic environment. As such the observation is designed to be as unobtrusive as possible in order to minimise the impact on participants' behaviour. Obviously introducing monitoring technology into people's homes is intrusive, but as the study will take place over a number of months it is hoped that the novelty will have time to wear off. The examples detailed above show that there is precedent for people allowing researchers to record interactions with technology and associated social behaviour in their homes. While we will not be able to incentivise participants to the level of a $£ 500 \mathrm{gift}$ (ACB, 2006), the very fact that researchers are interested in seemly mundane details of their behaviour and opinions about media confers upon these a sense of significance and value. The videoing of everyday activity and reflective interviews for analysis and dissemination parallels in some ways the production practices of factual or reality television, conventions which will probably be familiar to participants. To be the focus of attention and publically represented may be an attractive prospect akin to appearing in a documentary.

At the same time it is important that participants do not feel as though they are under constant and/or invasive surveillance. Data collection will not be continuous but will take place during sample periods; participants will be notified in advance of research activity and will always have the option of withdrawing their consent. Although our intention is to try to access media use that occurs throughout household space, the use of video observation will be confined to a living area. This means that many details of interactions not captured on video will only be available through interviews, when the participant has control over the information disclosed. The sharing and discussion of video and other data during interviews and workshops will make material participants have provided available to them and involve them in the process of making sense of it.

In this paper we have outlined some aspects of the relationship between video as a research tool and the study of interactions around media in households; and sketched how we intend to employ video in the methodology of the UMH project in light of the challenges that this presents. We believe that video will allow us to actually observe and code the different features and contexts of so-called 'lean back' (passive) and 'lean forward' (active) interactions with media, thereby producing richer insights than if we relied on accounts of reported behaviour.

The authors wish to acknowledge the support of Horizon Digital Economy Research, RCUK grant EP/G065802/1.

\section{REFERENCES}

Coughlan, T., Collins, T.D., Adams, A., Rogers, Y., Haya, P. A., Martin, E. (2012) The conceptual framing, design and evaluation of device ecologies for collaborative activities. International journal of human-computer studies 70(10), 764778.

Deacon, D., Pickering, M., Golding, P., Murdock, G. (1999) Researching communications: a practical guide to methods in media and cultural analysis. Arnold, London.

Evans, E. (2011) Transmedia television: audiences, new media, and daily life. Routledge, London.

Gauntlett, D. (1998) Ten things wrong with the "effects model". In Dickinson, R., Ramaswani, H., Linne, O. (eds), Approaches to audiences. Arnold, London.

Hill, A. (2005) Reality TV: audiences and popular factual television. Routledge, Abingdon.

Pink, S. (2007) Doing visual ethnography: second edition. Sage, London.

Martindale, S. (2008) Shakespeare on film: viewing Shakespeare inside the classroom and out. English Drama Media 10, 19-22.

Morley, D. (1986) Family television: cultural power and domestic leisure. Comedia, London.

Ofcom. (2010) Media lives: research overview 2005-2010. stakeholders.ofcom.org.uk/marketdata-research/media-literacy-pubs/ (7/6/12).

Ofcom. (2011) Media lives - wave 7: summary report. stakeholders.ofcom.org.uk/market-dataresearch/media-literacy-pubs/ (7/6/12).

Pearson, S., Barwise, P. (2006) PVRs and advertising exposure: a video ethnographic study. acbuk.net/projects-and-news.php (2/5/12).

Reeves, S. (2011) Designing interfaces in public settings: understanding the role of the spectator in human-computer interaction. Springer, London.

Wood, H. (2007) Television is happening: Methodological considerations for capturing digital television reception. European journal of cultural studies, 10, 485-506. 